\title{
Antifungal activity of Bacillussp. Gn-A11-18isolated from decomposing solid green household waste in water and soil against Candida albicans and Aspergillus niger
}

\author{
Azeddin El Barnossi $^{l^{*}}$, Fatimazahrae Moussaid ${ }^{1} \&$ Abdelilah Iraqi Housseini $^{l}$ \\ ${ }^{1}$ BiotechnologyLaboratory, Faculty of Sciences Dhar El Mahraz, Sidi Mohammed Ben Abdellah University, Fez-Atlas, Morocco \\ ${ }^{1 *}$ Corresponding author: ${ }^{*}$ e-mail: azeddin.elbarnossi@usmba.ac.ma

\begin{abstract}
Candida albicans an opportunistic pathogenic fungus causes many infections in humans. Whereas Aspergillus niger is a fungus that can produce ochratoxins, a group of extremely dangerous secondary metabolites that are classified as potentially carcinogenic to humans and also causing deterioration in grapes, strawberries, etc. The purpose of the current study is to isolate, purify, identify and characterize new microorganisms associated with solid green household waste for the control of $C$. albicans and $A$. niger. The antifungal activity of bacterial isolates was carried out in vitro by the agar plug diffusion method, the disk and well diffusion method. The isolate that showed promising activity has been identified by those macroscopic, microscopic and biochemical characteristics. The results obtained in the course of this study showed the isolation of an isolate named Gn-A11-18, which was shown to have significant inhibitory activity with a $42.66 \%$ inhibition percentage against $A$. niger and a $44.66 \mathrm{~mm}$ inhibition diameter against $C$. albicans compared to the controls. The identification of Gn-A11-18 isolate has shown that this isolate belongs to the genus Bacillus with a similarity to Bacillus subtilis and Bacillus tequilensis. In the light of the results of this study, we can suggest that the bioactive compound of Bacillus sp. Gn-A11-18 could become a biological alternate that could have an important role to fight against $C$. albicans and $A$. niger.

Keywords:A. niger, Antifungal activity, C. albicans, green household waste, recovery
\end{abstract}

\section{Introduction}

The quantity of household waste in Morocco is increasing due to population growth, rapid urbanization, a growing economy, and rising living standards [1]. This increase may have a negative impact on the environment and human health [2]. Currently the recovery of solid waste is the greatest challenge for a large part of the social, scientific and also economic class. In the literature, there are two main solid waste recovery mechanisms including composting (aerobic composting and vermi-composting) [3] and energy (incineration, granulation, biomethanization) [4-6]. However, until now, information on the recovery of microorganisms associated with the digestion of solid householdwaste in the natural environment remains unknown. In addition, the valorization of these microorganisms to control $A$. niger and $C$. albicans to our knowledge has not been done before.

A. niger is a fungus that is capable of producing ochratoxins, a group of extremely dangerous secondary metabolites which are classified as potentially carcinogenic to humans $[7,8]$ and also causing deterioration in grapes, strawberries, apples, sweet oranges and cherry tomatoes $[9,10,7]$. While C. albicans is a commensal organism and is frequently found in the gastrointestinal tract, urogenital tract, mouth, skin and also in the respiratory tract in humans and other mammals $[11,12]$. C. albicans is also a pathogenic fungus responsible for about $30 \%$ of patients with nosocomial infection and candidiasis, especially of the pulmonary type, which causes high morbidity and mortality in immunocompromised people [12].

Several current research studies have been focused on the control study against $C$. albicans and $A$. niger, including $\mathrm{Xu}$ et al.[13]which were used to control $C$. albicans by the use of coumarin, Kim and Kang[14]were used cell-free supernatant of a probiotic strain, Pediococcus acidilactici HW01 to control $C$. albicans, other researchers have been shown that probiotic bacteria have significant antifungal effects against $C$. albicans[15]. Whereas Mustapha et al.[16] have been controlling $A$. niger with biopolymer films containing turmeric oil, An et al.[17] have been shown that $\alpha$-terpineol and terpene-4-ol, the critical compounds in tea tree oil, exert antifungal activities in vitro and in vivo against $A$. niger, Devipriya and Roopan [18] use the plant extract from Cissus quadrangularis to fight against $A$. niger. Most of these research studies have focused on the use of essential oils from some plants and/or their extracts, while the control of C. albicans and $A$. niger by the use of microorganisms has been poorly documented.

The resistance of fungal microorganisms, especially $C$. albicans and $A$. niger, to commercially available antifungals is a very relevant factor because it is often associated with high morbidity and mortality [19]. Therefore, research efforts must be intensified to find new bioactive molecules with a minimum of side effects to 
control pathogenic and phytopathogenic fungi in general, $C$. albicans and $A$. niger in particular.

The present study was designed to recover microorganisms associated with solid green household waste (banana, pomegranate and tangerine wastes) decomposing in water and soil. The principal objective of which was to isolation, purification, characterization and identification of new bacteria producing bioactive molecules effective against $C$. albicans and $A$. niger.

\section{Materials and methods}

\subsection{Pathogens and phytopathogens}

The two species pathogenic C. albicans ATCC 10231 and phytopathogenic $A$. niger have been provided by Biotechnology Laboratory, Faculty of Sciences Dhar El Mahraz, Sidi Mohammed Ben Abdellah University, FezAtlas, Morocco. These two species have been verified by their macroscopic (appearance, shape, storyteller, odor, color, etc.) and microscopic (mycelial filaments, presence or absence of anastomosis loops and partitions, special structures, fruiting, spore and conidiophore diameter, etc.) characteristics using lactophenol cotton blue for $A$. niger[20] and methylene blue for C. albicans [21].

\subsection{Isolation of antagonistic bacterial strains}

Antifungal bacterial isolates have been isolated from solid green household waste (banana, pomegranate and tangerine waste) decomposing in water and soil. Briefly, $10 \mathrm{~g}$ of waste was collected in accordance with the Pochon and Tardieux[22], cut and then crushed in $100 \mathrm{ml}$ of sterile spring water. The suspension is then shaken for $2 \mathrm{hrs}$ in order to release as much microbial load as possible [1]. Isolation was carried out by the suspension-dilution technique, $0.1 \mathrm{ml}$ of each dilution $\left(10^{-1}\right.$ to $\left.10^{-6}\right)$ was separately sown on the surface by spreading on the MEA medium (Malt Extract Agar) modified by enrichment with $7 \%(\mathrm{v} / \mathrm{v})$ waste extract. After spreading and incubation at $30{ }^{\circ} \mathrm{C}$ in the dark for $48 \mathrm{hrs}$. The bacterial colonies have been purified by the striation method in the same medium and under the same isolation condition.

\subsection{Screening for in vitro inhibitory effects of $\mathbf{G n}$ - A11-18 isolate}

\subsubsection{Agar plug diffusion method}

The screening test for new antifungal bacterial isolates have been performed using the agar plug diffusion method [23]. The pure bacterial isolates have been cultured on the MEA medium. After 7 days of incubation at $30^{\circ} \mathrm{C}$ in the dark, plugs (6 $\mathrm{mm}$ in diameter) were cut by a die and placed on the MEA medium surface which was seeded with $C$. albicans ATCC 10231. In the case of $A$. niger, the screening of new antifungal bacterial isolates was also carried out on the MEA medium, but by means of direct confrontation in accordance with the [24]. The inoculated petri dishes have been incubated at $30^{\circ} \mathrm{C}$ in the dark and in an atmosphere saturated with moisture. The inhibition diameter and inhibition percentage have been determined after 48 hrs and 7 days of incubation for $C$. albicans and $A$. niger respectively $[25,26]$.

\subsubsection{Disk and well diffusion method}

The Gn-A11-18 isolate which showed promising inhibitory activity against $C$. albicans and $A$. niger has been cultured in three replicates in Erlenmeyer $(100 \mathrm{ml})$ each containing $50 \mathrm{ml}$ of sterile malt extract medium. After 7 days of incubation at $30^{\circ} \mathrm{C}$ in the dark and in a humidity saturated atmosphere. The suspensions have been centrifuged at $5000 \mathrm{rpm}$ for $10 \mathrm{~min}$, then filtered by wattman paper and millipore filters $(0.45$ then $0.22 \mathrm{~m}$ in diameter) under aseptic conditions. The evaluation of the filtrate of $\mathrm{Gn}$ A11-18 isolate has been performed by the disk diffusion method [27], and by the well diffusion method [28]. Petri dishes containing the MEA medium have been sown with $C$. albicans and inoculated with $A$. niger. Wattman paper disks (6 $\mathrm{mm}$ in diameter) have been deposited on the surface of the inoculated media and impregnated with 20 $\mu \mathrm{l}$ filtrate [25] and wells (6 $\mathrm{mm}$ in diameter) have been made by a sterile die on the inoculated media, then filled with 1001 filtrate [28]. The inoculated petri dishes have been incubated at $30^{\circ} \mathrm{C}$ in the dark. The inhibition diameter and inhibition percentage have been determined after 48 hrs and 7 days of incubation for C. albicans and A. niger respectively $[25,26]$.

\subsection{Characterization of optimized antifungal activity conditions of $\mathrm{Gn}-\mathrm{A} 11-18$ isolate}

The production of the antifungal metabolites of Gn-A1118 isolate has been performed using four culture media; Malt extract (ME), Sabourant (SB), Yeast and Malt extract $(\mathrm{YM})$ and nutrient broth (NB). Briefly, Erlenmeyer $(50 \mathrm{ml})$ containing $25 \mathrm{ml}$ of each culture medium have been inoculated with the culture of Gn-A11-18 isolate $48 \mathrm{hrs}$. old. After incubation at $30^{\circ} \mathrm{C}$ for $48 \mathrm{hrs}, 10 \mathrm{ml}$ aliquots have been sampled, centrifuged at $5000 \mathrm{rpm}$ for $10 \mathrm{~min}$ [19]. The supernatants have been filtered through Millipore filters $(0.45$ and $0.22 \mathrm{~m}$ in diameter) and tested using the well diffusion method [28]. By the same process, the production of the antifungal metabolites of Gn-A11-18 isolate has been carried out using the liquid malt extract medium at different $\mathrm{pHs}$ from 1 to 10 , the $\mathrm{pH}$ has been adjusted by $\mathrm{KOH} 1 \mathrm{~N}$ and $\mathrm{H}_{3} \mathrm{PO}_{4} 1 \mathrm{~N}$ and incubated for 48 hrs at different temperatures $\left(25,30,37\right.$ and $\left.44{ }^{\circ} \mathrm{C}\right)$.

\subsection{Gn-A11-18 isolate identification}

Gn-A11-18 isolate with high antifungal activity against $A$. niger and $C$. albicans has been identified on the basis of macroscopic, microscopic and biochemical characteristics. Staining of Gram, spore and catalase tests have been carried out for the first time. Then, the biochemical characteristics of the Gn-A11-18 isolate were tested using API 20E gallery according to the method described by Logan and Berkeley [29]. Growth in the NB medium at different $\mathrm{pHs}$ from 4 to $10, \mathrm{pH}$ has been adjusted by $\mathrm{KOH}$ 
$1 \mathrm{~N}$ and $\mathrm{H}_{3} \mathrm{PO}_{4} 1 \mathrm{~N}$, growth at different temperatures $(25$, $30,37,44$ and $50{ }^{\circ} \mathrm{C}$ ) and growth in the NB medium containing different $\mathrm{NaCl}$ concentrations $(0,2,4,6,8$ and $10 \%(\mathrm{w} / \mathrm{v}))$ have also been tested [30].

\subsection{Statistics analysis}

All tests and experiments have been repeated three times. The results have been designed and processed using GraphPad prism 8 software. The statistical analysis of the results obtained was carried out using IBM SPSS 20 Statistics for Windows software, the Duncan's Multiple Range Test method, a student t-test and an analysis of variance (ANOVA I) at the threshold of $\alpha=5 \%$ [1].

\section{Results and discussion}

\subsection{Isolation and identification of Gn-A11-18 isolate}

All bacterial isolates associated with green household waste (tangerine, banana and pomegranate waste) decomposing in water and soil over time (from February to June 2018) have been purified and grown in the same isolation medium, we have isolated 226 isolates (Fig. 1), where the highest number (51 and 49 isolates) have been isolated from the pomegranate and tangerine waste digested in the soil respectively (Fig. 1). The antifungal activity of these 226 isolates has been evaluated by the agar plug diffusion method, only 5 isolates that have shown antifungal activity, and especially the isolate named Gn-A11-18 which has been shown a promising activity against $C$. albicans ATCC 10231 and $A$. niger. The results of the cultural and biochemical studies of isolate Gn-A11-
18 are presented in table (1). This isolate is a gram positive, capped, rod-shaped bacillus grouped into pairs and chains, forming the endospores (Fig. 2), it has been shown a positive reaction to the catalase test, for $\beta$ galactosidase, gelatinase, acetoin production, Citrate utilization, Nitrate reduction and for the use of carbonaceous substrate (D-Glucose, D-Mannitol, Inositol, D-Sorbitol, D-Sucrose, D-Melibioses and Tonsil), while it had been negative for the use of carbonaceous substrate (L-rhamnose and L-arabinose), Arginine dihydrolase, Lysine decarboxylase, Ornithine decarboxylase, $\mathrm{H}_{2} \mathrm{~S}$ production, Urease, Tryptophan deaminase and Indole production. In addition, it has been able to grow at a temperature of $50^{\circ} \mathrm{C}$, and over a wide $\mathrm{pH}$ range of 4 to 10 and a $\mathrm{NaCl}$ concentration between 0 and 4\% (Table. 2). Based on the macroscopic, microscopic and biochemical characteristics that have been performed during the course of this study, Gn-A11-18 isolate belongs to the genus Bacillus with a great similarity to Bacillus subtilis and Bacillus tequilensis.

The Gn-A11-18 isolate is gathered at Bacillus spp isolated and characterized by Balouri et al.[19], but there are deficiencies especially for the use of carbonaceous substrates and also our isolate cannot grow at a concentration of $\mathrm{NaCl}$ above $4 \%$. It is also resembling $B$. subtilis described by Bouhairi[31], however Gn-A11-18 isolate it has been negative for the use of carbon substrate L-arabinose. Which suggests that the Gn-A11-18 isolate must be a subspecies of $B$. subtilis.

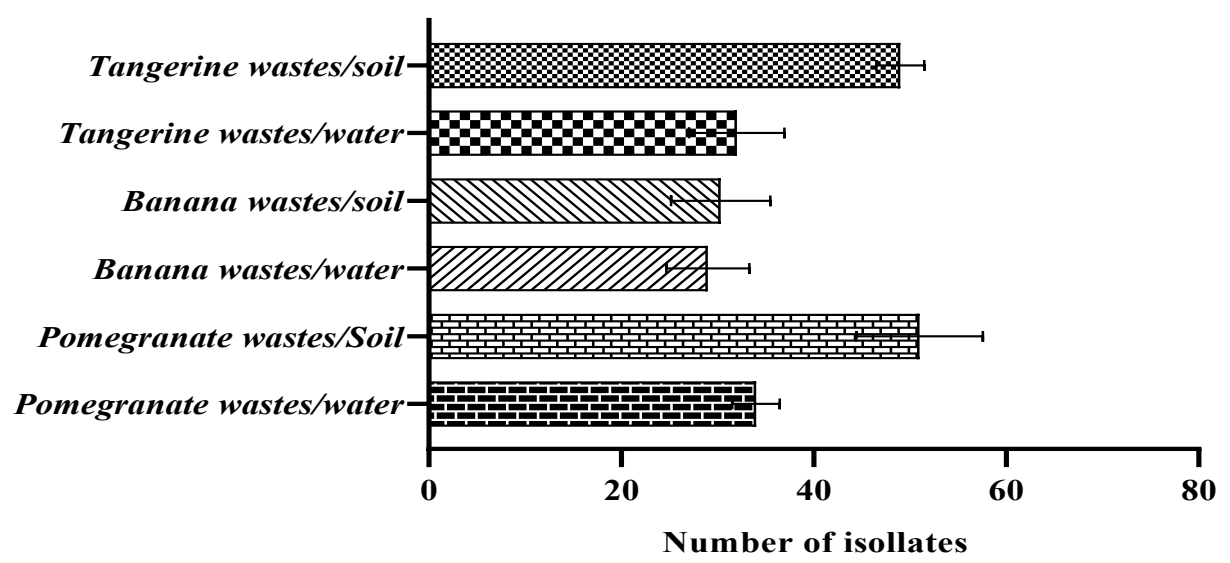

Fig.1.Number of isolates isolated from three types of decomposing waste in water and soil.
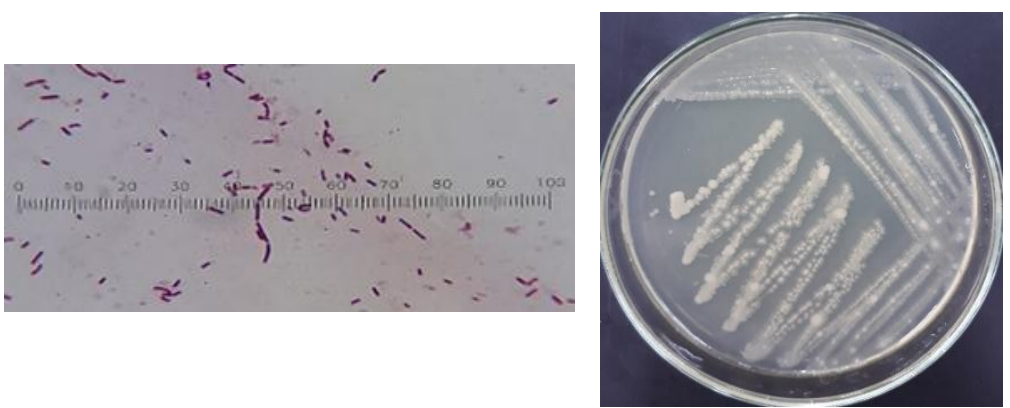
Fig. 2.Gram staining and cultural aspect of Gn-A11-18 isolate

Table 1.Cultural and biochemical characteristics of GnA11-18 isolate.

\begin{tabular}{|c|c|}
\hline Tests & Results \\
\hline \multicolumn{2}{|l|}{ Biochemical tests } \\
\hline$\beta$-galactosidase & + \\
\hline Arginine dihydrolase & - \\
\hline Lysine decarboxylase & - \\
\hline Ornithine decarboxylase & - \\
\hline Citrate utilization & + \\
\hline $\mathrm{H}_{2} \mathrm{~S}$ production & - \\
\hline Urease & - \\
\hline Tryptophan deaminase & - \\
\hline Indole production & - \\
\hline Acetoin production & + \\
\hline Gelatinase & + \\
\hline D-glucose & + \\
\hline D-Mannitol & + \\
\hline Inositol & + \\
\hline D-sorbitol & + \\
\hline L-rhamnose & - \\
\hline D-Sucrose & + \\
\hline D-Melibiose & + \\
\hline Amygdalin & + \\
\hline L-arabinose & - \\
\hline Nitrate reductase & + \\
\hline Catalase & + \\
\hline \multicolumn{2}{|l|}{ Growth at } \\
\hline $50^{\circ} \mathrm{C}$ & + \\
\hline $44^{\circ} \mathrm{C}$ & + \\
\hline $37^{\circ} \mathrm{C}$ & + \\
\hline $30^{\circ} \mathrm{C}$ & + \\
\hline $25^{\circ} \mathrm{C}$ & + \\
\hline \multicolumn{2}{|l|}{ Growth at PH } \\
\hline 4 & + \\
\hline 5 & + \\
\hline 6 & + \\
\hline 7 & + \\
\hline 8 & + \\
\hline 9 & + \\
\hline 10 & + \\
\hline \multicolumn{2}{|l|}{ Growth in $\mathrm{NaCl} \%$} \\
\hline 0 & + \\
\hline 2 & + \\
\hline 4 & + \\
\hline
\end{tabular}

\begin{tabular}{|l|l|}
\hline 6 & - \\
\hline 8 & - \\
\hline 10 & - \\
\hline
\end{tabular}

\subsection{In vitro inhibitory effects of Gn-A11-18 isolate}

In vitro evaluation of the antifungal activity by using agar plugs of Gn-A11-18 isolate against $C$. albicans and $A$. niger showed very high antifungal activity with an inhibition percentage of $42.66 \%$ against $A$. niger compared to the control (Fig. 3A and 3B) and also with an inhibition diameter of $44.66 \mathrm{~mm}$ against $C$. albicans compared to the control (Fig. 3C and 3D). Based on the promising results of the use of agar plugs from Gn-A11-18 isolate against $C$. albicans and $A$. niger, the evaluation of the filtrate of this isolate has been performed using the disk and well diffusion method. The results obtained are shown in figure (4) and table (2), these results show that the filtrate of GnA11-18 isolate has significant antifungal activity with an inhibition diameter of $31.33 \mathrm{~mm}$ and $42.33 \mathrm{~mm}$ against $C$. albicans and an inhibition percentage of $29.66 \%$ and $40.33 \%$ against $A$. niger by using the Disk and Well diffusion method, respectively. The filtrate of Gn-A11-18 isolate which has been autoclaved at $120^{\circ} \mathrm{C}$ for $30 \mathrm{~min}$ shows high activity against $C$. albicans and $A$. niger (Table. 2), which shows that the bioactive substance which has been present antifungal activity of the Gn-A11-18 isolate is thermoresistant.

Several scientific research studies have focused on the control of $C$. abicans and $A$. niger by the use of essential oils and substances of bacterial and fungal origin including Moussaid et al.[25], which have shown the isolation of an F27 isolate, the filtrate of this isolate has an antifungal activity with an inhibition diameter of $14.7 \mathrm{~mm}$ against $C$. albicans.Balouiri et al.[19] have been shown in this research that Bacillus spp isolated from Calotropis Procera Ait rhizosphere has shown an antifungal activity against $C$. albicans ATCC 102031 with an inhibition diameter of $36.33 \mathrm{~mm}$ on the YM (Yeast and Malt extract) medium. The study by Bamidele et al. [28] showed that the six strains of lactic acid bacteria showed varying degrees of antiCandida activity, especially Pediatric pentosaceus BTA 51 cucumber showed the largest inhibition zone of $14 \mathrm{~mm}$ at neutral $\mathrm{pH}$. Bulgasem et al. [32] have been found that the free cell supernatant produced by $L$. plantarum isolated from salad vegetables has significant antifungal activity against $C$. albicans with a $25 \mathrm{~mm}$ inhibition zone. Pudake et al.[33]in their studies evaluated seven biological control agents Trichderma hamatum, T. lignorum, T. koningi, $T$. harzianum, T. viride, Pseudomonas fluorescence and Gliocladium virens for their efficacy against $A$. niger, of 
these seven fungal antagonists tested, Trichoderma harzianum has been shown to be most efficient and has significantly recorded the highest proportion of mycelial inhibition (99.93\%). The current study shows that our Bacillus sp. Gn-A11-18 has the largest inhibition, especially against $C$. albicans, compared to other published studies.

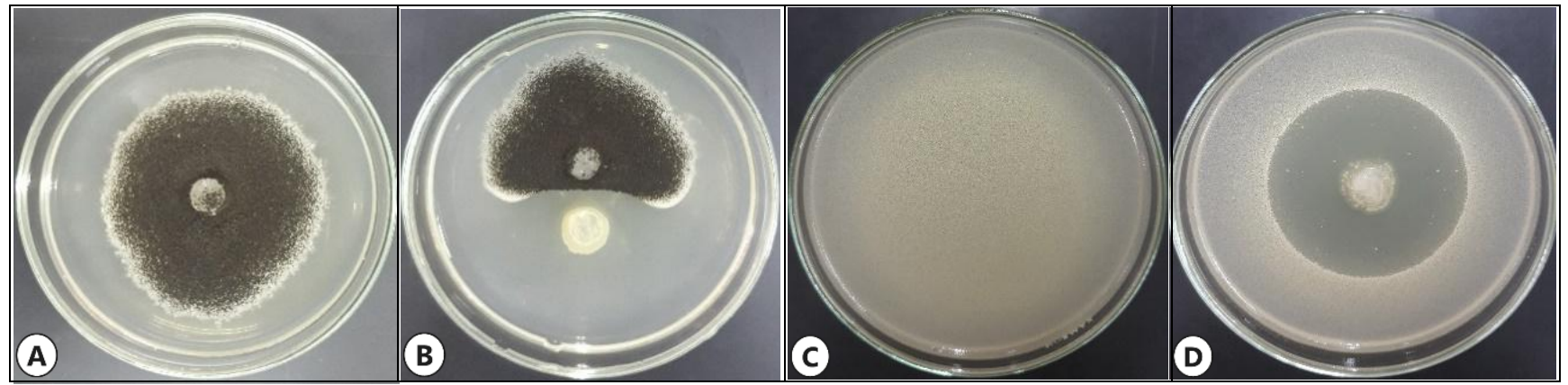

Fig. 3.Antifungal activity by agar plug diffusion method of Gn-A11-18 isolate against $A$. niger and $C$. albicans(A). Control of $A$. niger(B). Gn-A11-18 Isolate against $A$. niger(C). Control of $C$. albicans(D). Gn-A11-18 isolate against $C$. albicans.

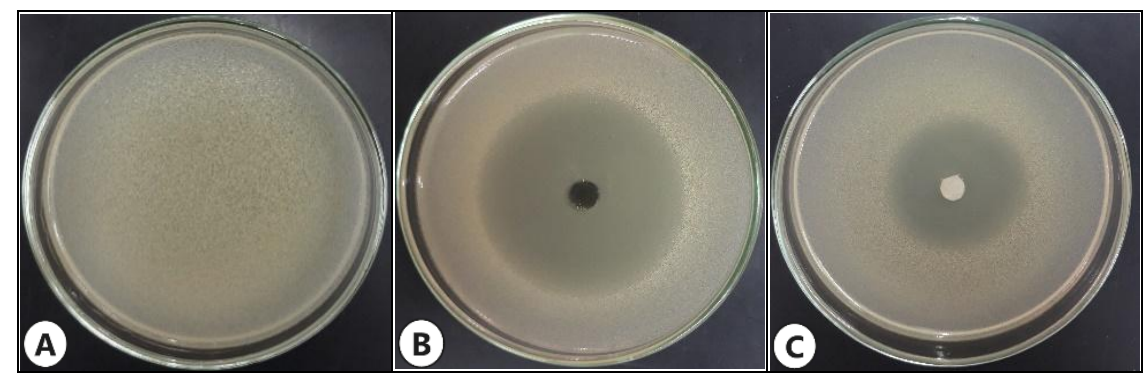

Fig. 4.Antifungal activity by disk and well diffusion method of filtrate from Gn-A11-18 isolate against $C$. albicans(A). Control of $C$. albicans(B). Gn-A11-18 isolate filtrate against C. albicans (well diffusion) (C). Gn-A11-18 isolate filtrate against $C$. albicans (disk diffusion).

Table 2.Percentage and inhibition diameter of the Gn-A11-18 isolate filtrate against $A$. niger and C. albicans

\begin{tabular}{|c|c|c|}
\cline { 2 - 3 } \multicolumn{1}{c|}{} & A. niger (\%) & C. albicans (mm) \\
\hline Agar plug of Gn-A11-18 isolate & $42.66 \pm 1.15$ & $44.66 \pm 0.58$ \\
\hline Gn-A11-18 isolate filtrate (disk diffusion) & $29.66 \pm 0.57$ & $31.33 \pm 0.58$ \\
\hline Gn-A11-18 isolate filtrate (well diffusion) & $40.33 \pm 0.57$ & $42.33 \pm 0.58$ \\
\hline $\begin{array}{c}\text { Gn-A11-18 isolate filtrate autoclaved at } 120^{\circ} \mathrm{C} \\
\text { (disk diffusion) }\end{array}$ & $27.66 \pm 0.57$ & $27.33 \pm 1.15$ \\
\hline $\begin{array}{c}\text { Gn-A11-18 isolate filtrate autoclaved at } 120^{\circ} \mathrm{C} \\
\text { (well diffusion) }\end{array}$ & $38.00 \pm 1.0$ & $41.00 \pm 1.73$ \\
\hline
\end{tabular}

\subsection{Effect of culture medium, temperature and $\mathrm{pH}$ on the antifungal activity of $\mathrm{Gn}-\mathrm{A} 11-18$ isolate against $A$. niger and $C$. albicans}

The different culture media, $\mathrm{pH}$ and temperatures have been examined to determine the culture medium, $\mathrm{pH}$ and optimal temperature of the antifungal activity of Gn-A1118 isolate against $A$. niger and $C$. albicans. The antifungal activity of isolate filtrate has been tested by the well diffusion method. The results obtained are summarized in table (3), according to which the highest antifungal activity was observed in the MEA medium compared to the NB, $\mathrm{YM}$ and $\mathrm{SB}$ media. With regard to $\mathrm{pH}$, the best $\mathrm{pH}$ of the antifungal activity which has been the neutral $\mathrm{pH}$ which gives the highest activity, $42.33 \mathrm{~mm}$ of inhibition against C. abicans compared to the control and a percentage of inhibition in the order of $40.33 \%$ against $A$. niger compared to the control. While the optimal temperature for the production of antifungal substances by Gn-A11-18 isolate is $30^{\circ} \mathrm{C}$ compared to the temperatures tested.

Bacillus species are capable of producing several antifungal metabolites on NB (Nutrient Broth), LB (Luria Bertani) and other simple and complex culture media. However, this is the first time the production of antifungal metabolites by Bacillus spp against $C$. albicans and $A$. 
niger has been reported with high antifungal activity in the MEA medium. Moreover, in contradiction to the results obtained by Balouiri et al.[19], which show that the YMA medium (Yeast Malt extract Agar) gives the highest antifungal activity of Bacillus spp. against $C$. albicans and also contrary to the study by Kumar et al.[34]which have been shown that the TSB medium gives the best production of the antifungal activity of $B$. subtilis, we have shown that MEA gives the best antifungal activity of the Gn-A11-18 isolate against $A$. niger and $C$. albicans. Neutral $\mathrm{pH}$ is the optimal $\mathrm{pH}$ of the production of antifungal metabolites of our isolate, this is in line with the studies of Bamidele et al.[28]which have shown that the neutral $\mathrm{pH}$ gives the best antifungal activity against $C$. albicans. The temperature of $30^{\circ} \mathrm{C}$ is the optimal temperature for the production of antifungal metabolites of Gn-A11-18 isolate against C. albicans and A. niger, our results are in accordance with those of [19, 25]which showed that the optimal temperature of antifungal activity is $30^{\circ} \mathrm{C}$, and as opposed to Bamidele et al.[28]which showed in their studies that the temperature $37^{\circ} \mathrm{C}$ is the optimal temperature for the production of antifungal substances from lactic acid bacteria to control C. albicans.

Table 3. Characterization of culture medium, temperature and $\mathrm{pH}$ of the antifungal activity of Gn-A11-18 isolate against $A$. niger and $C$. albicans

\begin{tabular}{|c|c|c|c|}
\hline \multicolumn{2}{|c|}{ Parameters } & A. niger(\%) & C. albicans(mm) \\
\hline \multirow{4}{*}{ pH } & 1.0 & $00 \pm 0.00$ & $00 \pm 0.00$ \\
\cline { 2 - 4 } & 2.0 & $00 \pm 0.00$ & $00 \pm 0.00$ \\
\cline { 2 - 4 } & 3.0 & $00 \pm 0.00$ & $00 \pm 0.00$ \\
\cline { 2 - 4 } & 4.0 & $19.66 \pm 0.58$ & $29.66 \pm 0.58$ \\
\cline { 2 - 4 } & 5.0 & $25.5 \pm 0.50$ & $28.66 \pm 0.58$ \\
\cline { 2 - 4 } & 6.0 & $40.33 \pm 0.58$ & $42.33 \pm 0.58$ \\
\cline { 2 - 4 } & 7.0 & $40.33 \pm 0.58$ & $42.33 \pm 0.58$ \\
\cline { 2 - 4 } & 8.0 & $34.67 \pm 0.58$ & $32.33 \pm 1.52$ \\
\cline { 2 - 4 } & 9.0 & $35.67 \pm 1.15$ & $32.66 \pm 1.52$ \\
\hline \multirow{4}{*}{ Temperature $\left({ }^{\circ} \mathbf{C}\right)$} & 10.0 & $35 \pm 1.00$ & $33.66 \pm 1.15$ \\
\cline { 2 - 4 } & 25 & $36 \pm 2.00$ & $39.33 \pm 0.58$ \\
\cline { 2 - 4 } & 30 & $40.33 \pm 0.57$ & $42.33 \pm 0.58$ \\
\cline { 2 - 4 } & 37 & $31.33 \pm 0.58$ & $36.67 \pm 0.58$ \\
\hline \multirow{4}{*}{ Culture media } & ME & $32.33 \pm 1.53$ & $32.67 \pm 1.15$ \\
\cline { 2 - 4 } & NB & $40.33 \pm 0.57$ & $42.33 \pm 0.58$ \\
\cline { 2 - 4 } & SB & $26.33 \pm 2.52$ & $27.67 \pm 1.53$ \\
\cline { 2 - 4 } & YM & $25.67 \pm 1.15$ & $26.67 \pm 1.15$ \\
\hline
\end{tabular}

ME. Malt extract, NB. Nutrient broth, SB. Sabourand, YM. Yeast and Malt extract

\section{Conclusion}

The present study shows promising antifungal activity of Gn-A11-18 isolate against $A$. niger and C. albicans. This isolate has been identified as Bacillus sp isolated from solid household waste digested in water and soil. This discovery suggests that the bioactive substance of this isolate may be new antifungal drugs to control pathogenic and phytopathogenic fungi and especially $C$. albicans and $A$. niger. However, further research is needed to complete the molecular identification of this isolate, the extraction of bioactive fractions, the physicochemical characterization of bioactive fractions, the purification and physicochemical characterization of antifungal compounds.

\section{References}

[1]A. El Barnossi, F. Moussaid, H.A. Iraqi, Decomposition of tangerine and pomegranate wastes in water and soil: characterization of physicochemical parameters and global microbial activities under laboratory conditions. Int. J. Environ. Stud76(3), 456-470 (2019).
[2]H.I. Abdel-Shafy, M.S.M. Mansour, Solid waste issue: Sources, composition, disposal, recycling, and valorization.Egypt. J. Pet27(4), 1275-1290 (2018).

[3]A. Cesaro, A. Conte, V. Belgiorno, A. Siciliano, M. Guida, The evolution of compost stability and maturity during the fullscale traetement of the organic fraction of municipal solid waste. J. Environ. Manage232, 264-270 (2019).

[4]E. Loginova, D.S. Volkov, P.M.F. Van de Wouw, M.V.A. Florea, H.J.H. Brouwers, Detailed characterization of particle size fractions of municipal solid waste incineration bottom ash. J. clean. prod207, 866-874 (2019).

[5]X. Shan, H. Peng, X. Ling, J. Li, Experimental investigation on particles characteristics in molten aluminum ligament granulation for waste energy recovery. Energy Procedia158, 4459-4464 (2019).

[6]B. Tao, A.M. Alessi, Y. Zhang, J.P. Chong, S. Heaven, J. Banks, Simultaeous biomethanisation of engogenous and imported $\mathrm{CO}_{2}$ in organically loaded anaerobic digesters. Appl. Energ247, 670-681(2019).

[7]J. Tian, Y. Wang, H. Zeng, Z. Li, P. Zhang, A. Tessema, X. Peng, Efficacy and possible mechanisms of perillaldehyde in 
control of Aspergillus niger causing grape decay. Int. J. Food Microbiol 202, 27-34 (2015).

[8]Q. Li, C. Li, P. Li, H. Zhang, X. Zheng, Q. Yang, M.T. Apaliya, B. Nana, A. Serwah, Y. Sun, The biocontrol effect of Sporidiobolus pararoseus Y16 against postharvest diseases in table grapes caused by Aspergillus niger and the possible mechanisms involved. Biol.Control113, 18-25(2017).

[9]N. Sonker, A.K. Pandey, P. Singh, N.N. Tripathi, Assessment of Cymbopogon citratus (DC) Stapf essential oil as herbal preservatives based on antifungal, antiaflatoxin, and antiochratoxin activities and in vivo efficacy during storage. J. Food Sci 79, 628-634 (2014).

[10]L. Tabti, M.E. Dib, N. Djabou, N.G. Benyelles, J. Paolini, J. Costa, A. Muselli, Control of fungal pathogens of Citrus sinensis L. by essential oil and hydrosol of Thymus capitatus L. J. Appl. Bot.Food. Qual87, 279-285 (2014).

[11]A. Erdogan, S.S. Rao, Small intestinal fungal overgrowth. Curr. Gastroenterol. Rep 17(4), 16 (2015).

[12]Z.L. Xu, S.R. Li, L. Fu, L. Zheng, J. Ye, J.B. Li, Candida albicans-induced acute lung injury through activating several inflammatory signaling pathways in mice. Int. Immunopharmacol72, 275-283 (2019).

[13]K. Xu, L. Wang, M.P. Chu, C. Jia, L. Wang, M.P. Chu, C. Jia, Activity of coumarin against Candida albicans biofilms. J. Mycol. Med29(1), 28-34 (2018).

[14]H. Kim, S.S. Kang, Antifungal activities against Candida albicans, of cell-free supernatants obtained from probiotic Pediococcus acidilactici HW01. Arch. Oral. Biol99, 113-119 (2019).

[15]V.H. Matsubara, H.M. Bandara, M.P. Mayer, L.P. Samaranayake, Probiotics as antifungals in mucosal candidiasis. Clin. Infect. Dis62, 1143-1153 (2016).

[16]F.A. Mustapha, J. Jai, N.H. Raikhan, Z.I.M. Sharif, N.M. Yusof, Response surface methodology analysis towards biodegradability and antimicrobial activity of biopolymer film containing turmeric oil against Aspergillus niger. Food Control99, 106-113(2019)

[17]P. An, X. Yang, J. Yu, J. Qi, X. Ren, Q. Kong, $\alpha$-terpineol and terpene-4-ol, the critical components of tea tree oil, exert antifungal activities in vitro and in vivo against Aspergillusniger in grapes by inducing morphous damage and metabolic changes of fungus. Food Control98, 42-53(2019).

[18]D. Devipriya, S.M. Roopan, Cissus quadrangularis mediated ecofriendly synthesis of copper oxide nanoparticles and its antifungal studies against Aspergillus niger, Aspergillus flavus. Mater. Sci. Eng80,38-44 (2017).

[19]M. Balouiri, S. Bouhdid, E.H. Harki, M. Sadiki, W. Ouedrhiri, S.k. Ibnsouda, Antifungal activity of Bacillus spp. Isolated from Calotropis Procera Ait. Rhizosphere against Candida albicans. Asian. J. Pharm. Clin. Res8(2), 213-217 (2015).

[20]A. Chauthan, J. Gruenberg, S. Arbefeville, T. Mettler, H.C. Brent, P. Ferrieri, Disseminated Hormgraphiella aspergillata Infection with Lung and Brain Involvement after Allogenic Hematopoietic Stem-Cell Transplantation in a 54-Year-Old Man. Lab. Med 1-6 (2019). Doi: 10.1093/labmed/lmz018.

[21]V. Gupta, K. Abhisheik, S. Balasundari, K.N. Devendra, K. Shadab, M. Anupama, Identification of Candida albicans using different culture media and its association in leukoplakia and oral squamoud cell carcinoma. J. oral. Maxillofac.Pathol23(1), 28-35 (2019).

[22]J. Pochon, P. Tardieux, Techniques d'analyse en microbiologie du sol (Saint Mandé : Edition de la Tourelle), 111p (1962).
[23]D. Ibrahim, C.C. Lee, Sheh-Hong L. Antimicrobial activity of endophytic fungi isolated from Swietenia macrophylla leaves. Nat. Prod. Commun 9(2), 247-250 (2014).

[24]E. Pereira, A. Santos, F. Reis, R.M. Tavares, P. Baptistaa, T. Lino-Netoc, C. Almeida-Aguiar, A new effective assay to detect antimicrobial activity of filamentous fungi. Microbiol. Res168, 15 (2013).

[25]F. Moussaid,A. EL Barnossi, N. Chahmi, A. Iraqi Housseini,Screening and selection of new microbial anticandidiasis. Mater.Today. Proc13(3), 1049-1054 (2019).

[26]J.A. Elegbede, A. Lateef, M.A. Azeez, T.B. Asafa, T.A. Yekeen, I.C. Oladipo, A.S. Hakeem, E.B. Gueguim-Kana, Silvergold alloy nanoparticles biofabricated by fungal xylanases exhibited potent biomedical and catalytic activities. Biotechnol.Prog(2019). Doi: org/10.1002/btpr.2829.

[27]M. Gajbhiye, J. Kesharwani, A. Ingle, A. Gade, M. Rai, Fungus-mediated synthesis of silver nanoparticles and their activity against pathogenic fungi in combination with fluconazole. Nanomedicine 5(4), 382- 386 (2009).

[28]T.A. Bamidele, B.A. Adeniyi, S.I. Smith, In viro, acidic, nonproteinaceous antifungal activities of lactic acid bacteria isolated from salad vegetables against human pathogenic Candida albicans. Africain. J. Clin. Exper. Microbiol20(2), 137-42 (2019). [29]N.A. Logan, R.C. Berkeley, Identification of Bacillus strains using the API system. J. Gen. Microbiol130(7), 1871-1882 (1984).

[30]K.H. Schleifer, Phylum III. Firmicutes Gibbons and Murry 1978 , 5. Bergey's Manual of Systematic Bacteriology, eds Vos P, et al. (Springer, New York), pp 19-1317 (2009).

[31]S. Bouhairi, Bacillus subtilis: characterization and application. Doctoral thesis, Mohamed V University, Faculty of Medicine and Pharmacy, Rabat, Morocco, thesis No. 24. pp. 1117/134 (2017).

[32]Y.B. Bulgasem, M.N. Lani, Z. Hassan, W.M. Wan Yusoff, S.G. Fnaish, Antifungal Activity of Lactic Acid Bacteria Strains Isolated from Natural Honey against Pathogenic Candida Species. Mycobiology44(4), 302-309 (2016).

[33]S.P. Pudake, D.G. Hingole, P.H. Ghante, P.B. Khaire, C.S. Swami, In-vitro evaluation of Phyto-extracts and bioagent against Aspergillus niger. Int. J. Chem. Stud7(2), 434-438 (2019).

[34]A. Kumar, P. Saini, J.N. Shrivastava, Production of peptide antifungal antibiotic and biocontrol activity of Bacillus subtilis. Indian. J. Exp. Biol47(1), 57-62 (2009). 